\title{
Synchronous Occurrence of B-Cell Non Hodgkin Lymphoma and Metas- tatic Small Cell Carcinoma of Lung
}

\author{
Umbreen Hashim*, Imran Ahmad and Shawana Kamran \\ Haematology Department, Shifa International Hospital, Islamabad, Pakistan.
}

\begin{abstract}
Synchronous occurrence of multiple malignancies i.e.: epitheliod and lymphoproliferative are rare but well reported. Here we have presenting a case of 82 year old male, known smoker, admitted at Shifa International Hospital Islamabad, with complaints of shortness of breath, productive cough, weight loss, generalized weakness and cervical lymphadenopathy.

The laboratory investigations; complete blood counts and peripheral blood showed patient is having absolute lymphocytosis with flow cytometric analysis performed on peripheral blood revealing B-cell Non Hodgkin lymphoma. However $\mathrm{p}^{53}$ deletion was not detected on using fluorescence in-situ hybridization. Although bone marrow biopsy examination was surprisingly seen with multiple cohesive metastatic clumps and dispersed atypical cells with positivity of CKAE1/AE3, CD56, TTF1 giving diagnosis of metastatic lung carcinoma. Hence occurrence of both epitheliod and lymphoproliferative malignancy was made and reported in Pakistan most likely for the first time.
\end{abstract}

Keywords: Synchronous malignancies, Lymphoproliferative disorders, Metastatic tumor.

doi.org/10.21089/njhs.22.0084

\section{INTRODUCTION}

The presence of multiple malignancies in same patient whether synchronous (detected at same time) or metachronous (one cancer following another after a period of time) is a rare occurance [1].

Synchronous or metachronous occurrence are multifactorial due to various causes i.e.: age, sex, ethnicity, geographical distribution, immune-deficient status, infectious agents, prior chemotherapy and subtype of tumors [2].

Lung cancer represents the principal cause of cancer mortality worldwide. The World Health Organization (WHO) classifies lung cancer into two subtypes: 1) Non-small cell lung cancer (NSCLC), which represents $85 \%$ of all lung carcinomas, and mostly comprises of adenocarcinoma, squamouscell, and large-cell carcinoma. 2) Small cell lung cancer (SCLC), represents $14-15 \%$ of cases [3].

Lymphoproliferative disorders (LPDs) are a malignant group of disorders mostly arising from lymphoid tissues, in which excessive lymphocyte proliferation leads to monoclonal lymphocytes and associated with immunity dysfunction [4]. In this article we are presenting a unique case.

\section{CASE REPORT}

We report a case of 82 year old male, known heavy smoker with complaints of shortness of breath, productive cough,

*Address correspondence to this author at the Haematology Department Shifa International Hospital Islamabad, Pakistan.

E-mail: umbreenhashim@yahoo.com weight loss, generalized weakness and cervical lymphadenopathy.

His initial laboratory investigations showed white blood cell count $49.37 \times 10^{9} / \mathrm{uL}$ predominantly with lymphocytes. His bone marrow aspirate sample for p53 deletion by using Fluorescence in situ hybridization was not detected. His immunophenotyping performed on a single cell suspension prepared from peripheral blood reveals an expanded population of B-Lymphoid cells which represent $70 \%$ of the total events. These are positive for CD45 (bright), CD19, CD20 (bright) and FMC7, while negative for CD5, CD23. These findings are suggestive of Non Hodgkin B-cell lymphoma, (Fig. 1).

His bone marrow biopsy showed effacement by a metastatic tumor, composed of cohesive groups of cells which showed relatively scantly cytoplasm, salt and pepper chromatin and increased mitosis (Fig. 2). Immuno-histochemistry showed this metastatic tumor to be strongly positive for CKAE1/AE3, CD56 and TTF1, while negative for LCA immunostain and suggesting of metastatic pulmonary small cell carcinoma (Fig. 3, 4).

\section{DISCUSSION}

Cancer survivors have an increased risk of developing secondary malignancies. Multiple primary malignancies in a single patient were first described in 1879 by Billroth. The North American Association of Central Cancer Registries (NAACCR) classifies multiple primary tumors into two categories: (1) Synchronous, in which the cancers occur at the

www.njhsciences.com 

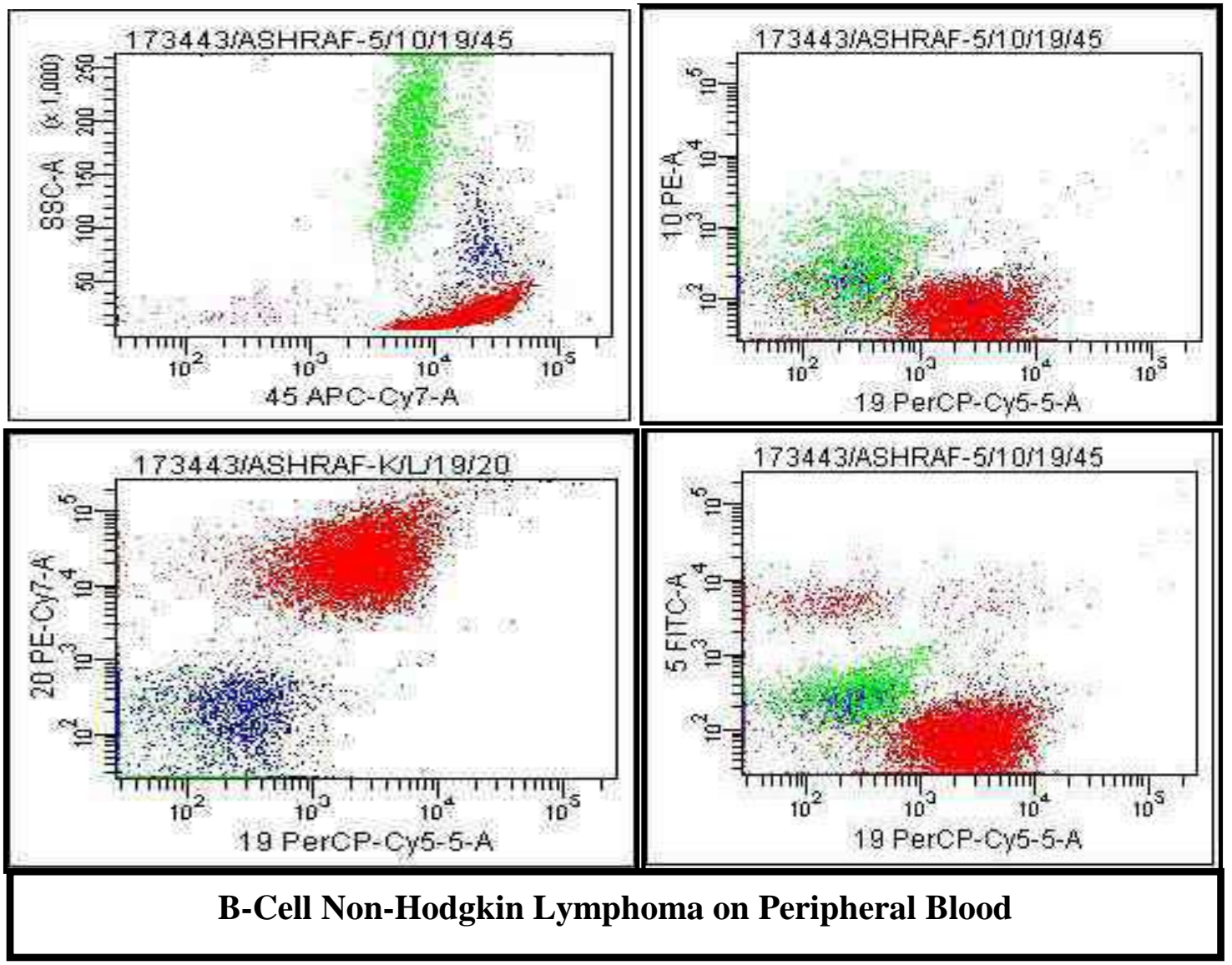

Fig. (1).

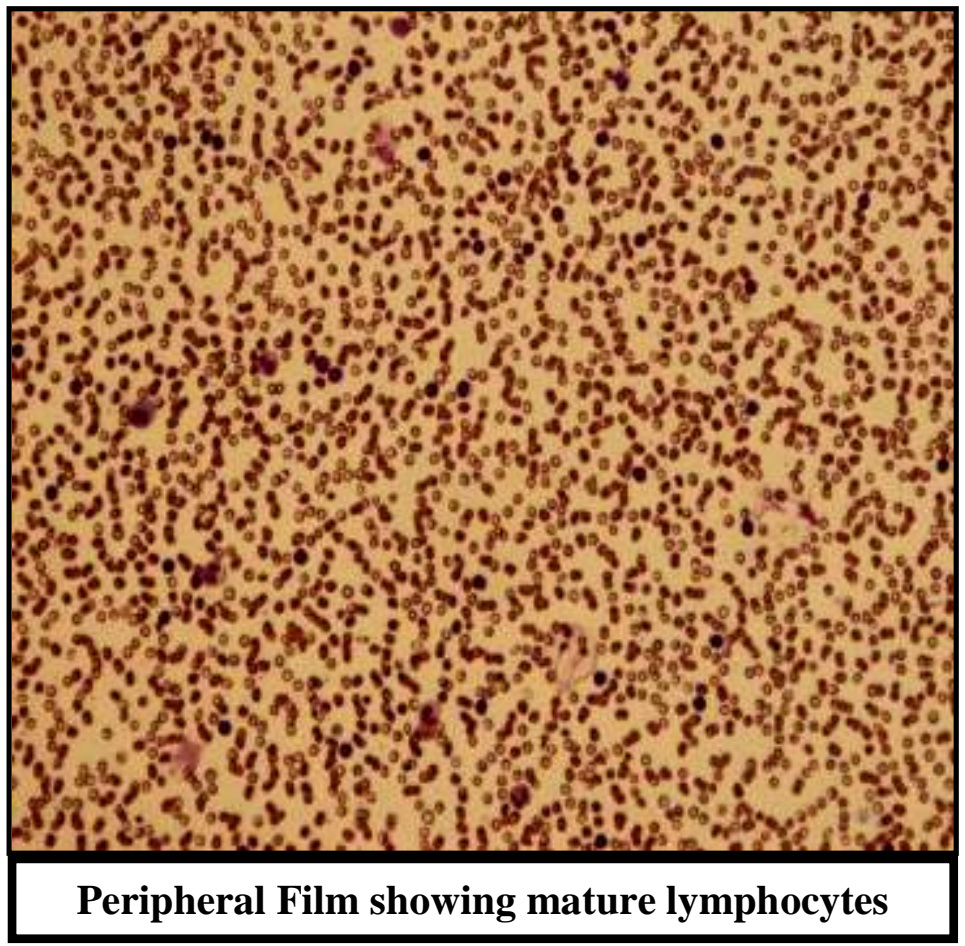

Fig. (2). 


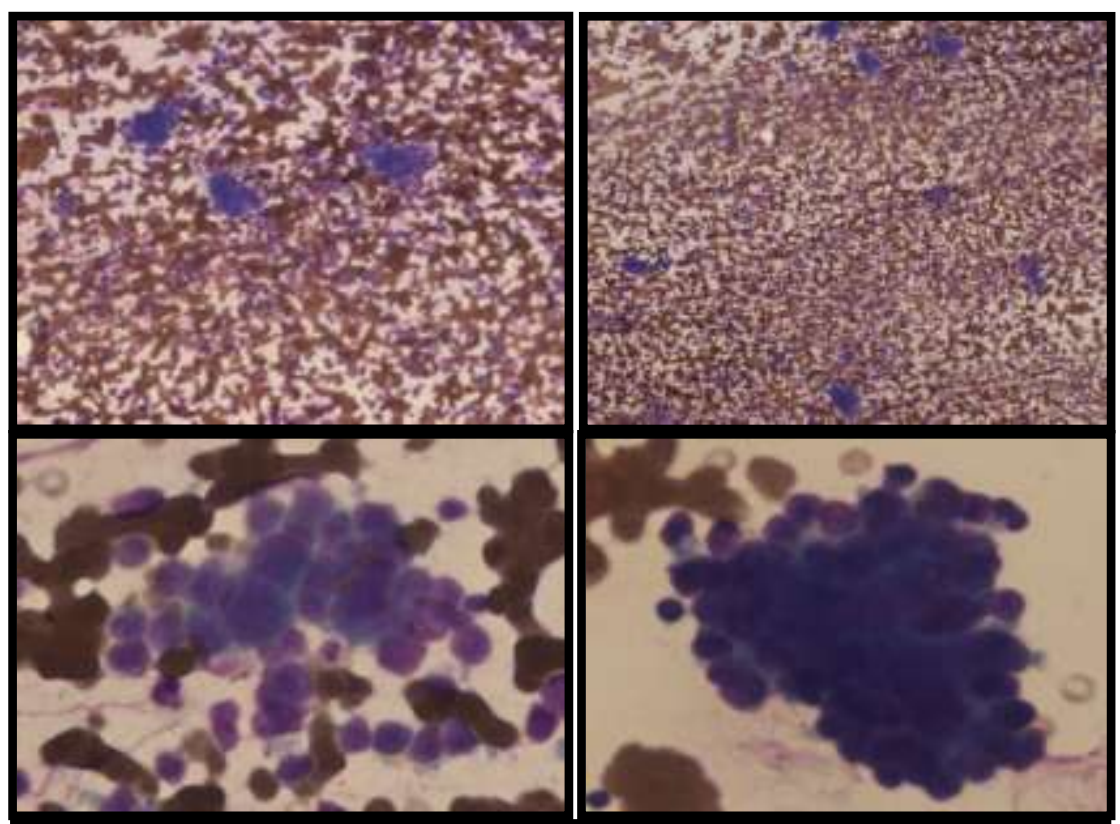

Bone marrow asnirate showing metastatic clumns

Fig. (3).

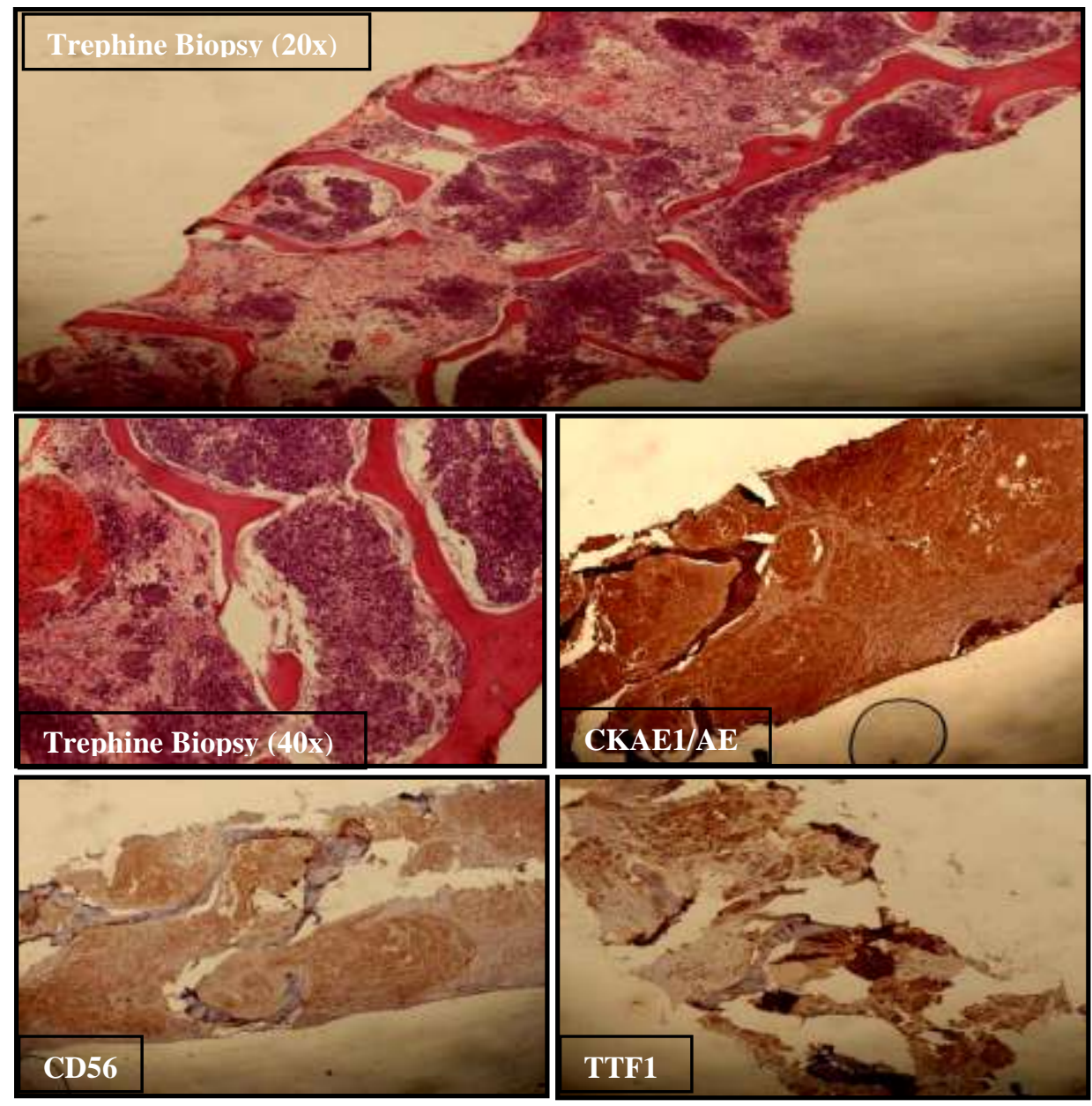

Fig. (4). 
same time (the Surveillance Epidemiology and End Results Program (SEER) definition is within two months) and (2) Metachronous, in which the cancers follow in sequence, that is, more than two months apart.

\begin{tabular}{|l|l|}
\hline \multicolumn{1}{|c|}{ Authors } & \multicolumn{1}{|c|}{ Synchronous Malignancies } \\
\hline Hyeon et $_{\text {al. }}{ }^{[2]}$ & $\begin{array}{l}\text { Synchronous double cancer of rectal diffuse } \\
\text { large B-cell lymphoma and squamous cell } \\
\text { carcinoma of lung. }\end{array}$ \\
\hline Chanel et $a l .^{[3]}$ & $\begin{array}{l}\text { Synchronous pulmonary adenocarcinoma and } \\
\text { extranodal marginal zone lymphoma of MALT } \\
\text { type. }\end{array}$ \\
\hline Rothenburger et al. ${ }^{[4]}$ & $\begin{array}{l}\text { Non-Hodgkin's lymphoma coexisting with } \\
\text { NSCLC. }\end{array}$ \\
\hline Rubiales et al. ${ }^{[5]}$ & $\begin{array}{l}\text { Synchronous occurrence of a small-cell lung } \\
\text { cancer and a Hodgkin lymphoma. }\end{array}$ \\
\hline Sun et al. ${ }^{[6]}$ & $\begin{array}{l}\text { Synchronous occurrence of pulmonary SCC } \\
\text { and MCL of lymph node. }\end{array}$ \\
\hline
\end{tabular}

MALT: Mucosa associated lymphoid tissue, NSCLC: Non small cell lung cancer, SCC: Squamous cell carcinoma, MCL: Mantle cell lymphoma.

The aetiology of synchronous may be recognized as the interaction between the immune system and carcinogenetic factors. Various risk factors have been described and recognized as contributing factors to the development of LPD. These may act in association, which results in a second malignancy, and includes immunodeficiency states, viruses (particularly the Epstein-Barr virus), chemotherapeutic agents, radiation exposure, pesticides and organic solvents, genetic susceptibility and life style which may cause certain malignancies to occur more commonly than expected [5].

Life style choices such as tobacco use and alcohol intake are related to multiple primary cancers. Therefore, patients with a primary malignancy who partake in such behavioural risk factors or who are obese are clearly at higher risk of subsequent malignancies. Additionally, a chronic immunologic stimulation via an infection, autoimmune, inflammatory, or allergic reaction may give rise to secondary malignancies. Identifying patients with risk factors would allow the medical team to potentially personalize treatment and surveillance hence minimising the risk of secondary malignancies [6-9].

\section{CONCLUSION}

further studies need to be completed in order to conclude the exact cause(s) of the rare occurrence of multiple simultaneous malignancies. After close examination of the current literature, it is likely that the coexistence of haematopathologic neoplasms is multifactorial. It is doubtful for this occurrence to be entirely dependent upon one factor since the literature clearly shows variable factors that have likely re- sulted in secondary malignancies. We also need to consider the diagnosis of these three malignant entities to the possibility of pure chance. The precise mechanism of our extremely rare case remains unknown; hence further investigation and monitoring of potential associated factors are needed.

In our patient we didn't know exact cause of this synchronous relationship of neoplasm as our patient died and we were not able to perform his cervical lymph node biopsy and FDG PET Scan which should have ideally been performed.

\section{CONFLICT OF INTEREST}

Declared none.

\section{ACKNOWLEDGEMENT}

Declared none.

\section{REFERENCES}

[1] Acharya P, Ramakrishna A, Kanchan T, Magazine R. Dual primary malignancy: a rare organ combination. Case Rep., Pulmonol., 2014; 2014:760631. DOI: $10.1155 / 2014 / 760631$

[2] Baliaka A, Cheva A, Pastelli N, Dimitriadis I, Sakkas L. AB 47. Incidental non-hodgkin lymphoma in a patient with squamous cell carcinoma of the lung: a case report. J. Thorac. Dis., 2012; 4 (Suppl 1): AB47. DOI: 10.3978/j.issn.2072-1439.2012.s047

[3] Dorantes-Heredia R, Ruiz-Morales J, Cano-Garcia F. Histopathological transformation to small-cell lung carcinoma in non-small cell lung carcinoma tumors. Transl. Lung Cancer Res. 2016; 5(4):401-412. DOI: $10.21037 /$ tlcr.2016.07.10

[4] Pezzuto A, Piraino A, Mariotta S. Lung cancer and concurrent or sequential lymphoma: two case reports with hypersensitivity to bevacizumab and a review of the literature. Oncol. Lett., 2015; 9(2):604-608.

[5] Fonseca D, Musthyala B, Ahmed F, Murthy S, Raju K. A tale of synchronous lung carcinoma and diffuse large B-cell lymphoma of ileum: a rare combination. Lung India. 2015; 32(4): 398-401. DOI: $10.4103 / 0970-2113.159598$

[6] Santos H, Benevenuto B, Filho E, Altemani A. Synchronous metastatic cutaneous squamous cell carcinoma and chronic lymphocytic leukaemia/small lymphocytic lymphoma in a cervical lymph node: case report of an unusual event. J. Clin. Exp. Dent., 2015; 7(5): e660-e664. DOI: 10.4317/jced.52643

[7] Park J, Lee J, Lim Y, Lee Y, Lee D. Synchronous occurrence of primary cutaneous anaplastic large cell lymphoma and squamous cell carcinoma. Ann. Dermatol., 2016; 28(4): 491-494. DOI: 10.5021/ad.2016.28.4.491

[8] Pandey U, Naraynan M, Karnik U, Sinha B. Carcinoma metastasis to unexpected synchronous lymphoproliferative disorder: report of three cases and review of literature. J. Clin. Pathol., 2003; 56(12): 970-1. DOI:10.1136/jcp.56.12.970

[9] Carson H. Unexpected Synchronous Non-Hodgkin's lymphoma encountered during the treatment of a previously-diagnosed carcinoma: report of three cases. 1996; 23(5-6): 625-629. DOI: $10.3109 / 10428199609054875$ 